\title{
Combining Argo profiles with a general circulation model in the North Atlantic. Part 2: Realistic transports and improved hydrography, between spring 2002 and spring 2003
}

\author{
Gaël Forget ${ }^{a},{ }^{*}$, Herlé Mercier ${ }^{b}$ and Bruno Ferron ${ }^{b}$
}

\author{
${ }^{a}$ Department of Earth, Atmospheric and Planetary Sciences, Massachusetts Institute of Technology, Room 54- \\ 1517, Cambridge, MA 02139, USA \\ ${ }^{\mathrm{b}}$ Laboratoire de Physique des Océans, UMR 6523, CNRS-Ifremer-UBO, Ifremer Centre de Brest B.P. 70, 29280 \\ Plouzané, France
}

\author{
*: Corresponding author : Forget G., email address : gforget@mit.edu, Tel: 617-253-5458. Fax: 617- \\ 253-4464.
}

\begin{abstract}
:
A set of Argo profiles collected in the North Atlantic between May 2002 and April 2003 is combined with a low-resolution general circulation model (GCM) using the adjoint method. Fitting the real hydrographic observations leads to vast improvements in the model circulation, including the sea surface height and the meridional heat transport. We find striking differences in basin-scale transports compared with previous assimilation experiments that use the same GCM and a similar spatial resolution. Based on forward modeling studies, it is argued that these differences are due to different assimilation experiment durations. Over 1 year, the hydrography interpolated with the GCM from Argo profiles better represents the contemporary structures than does a long-term averaged climatology. The GCM dynamics are robust enough to distinguish between contemporary hydrography and climatological hydrography.
\end{abstract}

Keywords: Data assimilation; 4DVAR; In situ observations; Argo; General circulation model 


\section{Introduction}

Idealized assimilation experiments (companion paper, Forget et al., 2007) predict that large-scale anomalies of the ocean hydrography and circulation can be identified by fitting (using the adjoint method) a low-resolution general circulation model (GCM) to a set of Argo profiles over a one year period, even if the amplitude of small-scale noise (that can be meso-scale eddy signals, waves, etc) is relatively large. Aside from the information content of sets of Argo profiles and the practicality of the estimation tool (Forget et al., 2007), a key question is whether GCM dynamics are consistent enough with the real ocean dynamics to yield estimates that can take full advantage of real observations. In recent years, efforts to constrain GCM solutions with all available real observations have pointed out some dramatic improvements upon free running GCM solutions (e.g. Stammer et al., 2002). Past this decisive first step, a legitimate expectation for GCM-Argo synthesis efforts is that they lead to improvements upon estimates of the long-term mean hydrography. It has yet to be demonstrated or otherwise that this goal can be met using currently available GCMs. This is the main motivation for this study that, complementing Forget et al. (2007), is an extended assessment of the degree to which GCM state estimation can take advantage of real Argo profile constraints.

Conclusions have to arise by evaluating GCM-Argo estimates based on independent information. One must recognize that, as we talk about the real ocean state, the possibilities remain severely limited by the availability of reliable independent information. For the circulation in particular, the optimistic predictions of the idealized experiments cannot be fully tested. We will mainly focus on the evaluation of the time-averaged GCM-Argo estimate using independent estimates of the long-term mean dynamic topography (from altimeter measurements, gravity measurements, and surface drifters) and mid-depth velocities (from subsurface float drifts; not from Argo float drifts) - this information is withheld for this purpose. The volume and heat transports will also be discussed and compared with previous inversions. We will emphasize striking contrasts between the present one-year assimilation experiment and a previous decade-long assimilation experiment (Stammer et al., 2004, and Köhl et al., 2003), both of which used the same GCM and a similar spatial resolution. For the hydrography, two high quality quasi-synoptic transects will be used to show that the GCM-Argo estimate is an improved representation of the contemporary ocean state compared with a long-term mean observed climatology (Reynaud et al., 1998). 
Differences between the contemporary hydrography and the climatological hydrography will be analyzed using GCM-based interpolation.

Modifications to the state estimation system of Forget et al. (2007) that were necessary to accommodate real data are presented in section 2. Section 3 discusses GCM-Argo misfits. The estimated circulation (section 4 and 5) and hydrography (section 6) are then evaluated using independent information. The final section summarizes the results and provides additional discussion.

\section{Estimation system}

As in Forget et al. (2007), the estimation system consists of correcting the T and S initial conditions of a GCM in order to better fit Argo profiles. For the present exercise, adjusting other variables (e.g. air-sea forcing or internal model parameters) was not necessary as initial condition adjustments allow major improvements in the fit to Argo data over one year (see below).

The domain is the North Atlantic, and the experiment duration is one-year. We employ the MITgcm (Marshall et al., 1997) and the adjoint method (also known as "4DVAR assimilation"). The GCM horizontal resolution is $1^{\circ} \cos ($ latitude). The reader is referred to Forget et al. (2007) for a more detailed presentation; below we focus solely on modifications to the estimation system described in Forget et al. (2007).

\subsection{Model set-up}

The spin-up integration starts in August 1998, and lasts three and a half years. The GCM integration over the following year (hereafter SPIN) is the first guess model solution of the state estimation problem. The spin-up integration is initialized with zero velocity, and with T and S fields from the Reynaud et al. (1998) hydrographic climatology. The spin-up duration is reduced compared with Forget et al. (2007) to reduce drifts away from the climatology, and thus improve the first guess model solution. The spin-up duration is not reduced to 0 though, to avoid initialization shocks (e.g. in kinetic energy) within the first guess model solution. The model is forced with the NCEP reanalysis fluxes (Kalnay et al., 
1996), plus a surface temperature and salinity relaxation towards the climatology (with a time-scale of 10 days).

\subsection{Data set}

The period during which the GCM solutions are compared with observations (hereafter the assimilation window) extends from May 2002 through April 2003. The 7356 temperature (T) and 5441 salinity $(\mathrm{S})$ profiles collected by Argo profilers in the North Atlantic during this period are the primary upper ocean data set. They were obtained from the Coriolis data center (http://www.coriolis.eu.org). The best-sampled area is to the north of $30^{\circ} \mathrm{N}$ (Fig. 1), whereas to the south the Argo network had not yet reached its deployment objectives in 2002. The idealized experiments of Forget et al. (2007) illustrate that large $\mathrm{T}$ and $\mathrm{S}$ errors may be found in the areas that are deprived of observations. To compensate, the primary data set is complemented with climatological profiles to the south of $30^{\circ} \mathrm{N}$ in the upper ocean (locations are shown by Fig. 1), and over the whole domain below $2000 \mathrm{~m}$ (i.e. in layers where Argo does not provide observations). In total, the number of climatological observations used is close to the number of Argo observations.

We note that these complementary climatological observations can only add benefit if the climatology is a better estimate of the hydrography in 2002/2003 than is the first guess model solution (in section 3, we will demonstrate this to be the case). Also, they can only have a regional impact because the assimilation window, over which the dynamics propagate the information, is only a year. As the upper and deep flows can be coupled, the deep climatological constraint can have an impact on the upper ocean circulation; this impact is discussed in section 5 .

\subsection{Uncertainties}

The estimation process consists of a minimization of $J(x)=J_{b}+J_{o}$ (appendix: Eq. 1 ), where $x$ are the initial conditions for $\mathrm{T}$ and $\mathrm{S}$. The $J_{b}$ term penalizes initial condition corrections, and the $J_{o}$ term penalizes the misfit of the model solution to the observations. Both terms involve normalization by inverse squared uncertainties (see Forget et al., 2007). The initial condition uncertainties only vary with depth. At each level they are computed 
as the root mean squared difference between the first guess solution and the Argo data, first binned into $3 \times 3^{\circ}$ boxes and time averaged. Fig. 2 shows the two sets of initial condition uncertainty profiles (dashed lines) used in the two "steps" of the estimation process (see next section). For observations, the newly available variance maps of Forget and Wunsch (2006) are used here to account for a spatially varying representation error (i.e. small-scale noise or signals). The Forget and Wunsch (2006) estimate improves upon the error estimate that was used in the optimization (described by Forget 2005 in details). The Forget and Wunsch (2006) estimate eventually needs to be further improved though, and efforts to estimate instrumental errors for individual floats are desirable.

\subsection{Initial adjustment period}

Idealized experiments (Forget et al., 2007) have shown that energetic adjustments to dynamically unbalanced initial condition perturbations lead to a deterioration of the estimated circulation in the first two months. This is not crucial here because we focus on the annual mean circulation. Furthermore, we add a buffer period of two months before the assimilation window, to reduce contamination of the one-year estimate. We do a first optimization (step 1) of initial conditions at the beginning of March 2002, starting from SPIN. The resulting solution (iteration 20) thus shows only a small excess of kinetic energy at the beginning of the assimilation window, despite a large one at the beginning of the buffer period (Fig. 3).

Next, we do a second optimization (step 2) that enables us to further reduce the impact of initial adjustments on the estimates. Step 2 is similar to step 1, except for the first guess initial condition (in March 2002). The new first guess initial condition is the March 2003 optimized state from step 1. As most errors corrected by step 1 are associated with the low frequency model drift, step 2 thus starts closer to the observations than does step 1 (Fig. 2, dashed lines). Consequently, the initial condition corrections that are required to fit the observations are smaller in step 2 than in step 1, and the resulting initial adjustments are less energetic (Fig. 3). The result of step 2 (iteration 28) over the assimilation window, which excludes the buffer period of two months, is the estimate discussed below (hereafter ARGO1). 


\section{$3 \quad$ Fitting Argo profiles}

Assuming perfect error statistics, least squares theory predicts that the average of $J_{o}$ contributions should be close to unity after assimilation. In ARGO1, the average of $J_{o}$ for Argo observations is indeed reasonably close to unity (Fig. 4) - this simply is a consistency check of the error estimates chosen in section 2.3. It is the comparison of $J_{o}$ for the different large-scale solutions that is most interesting. First, $J_{o}$ is larger for SPIN than for the climatology (from which the model is spun-up), and this reflects the accumulation of model and forcing errors over four years of unconstrained spin-up. Second, $J_{o}$ is $3-5$ times smaller for ARGO1 than for SPIN (Fig. 4), because large-scale misfits to Argo profiles are reduced upon moving from SPIN to ARGO1 (Fig. 1). Third, and most important, $J_{o}$ is smaller for ARGO1 than for the climatology (except for T near the surface); ARGO1 better represents the large-scale hydrographic structures in 2002-2003 than does the climatology (as further illustrated in section 6).

The values of $J_{o}$ reached in ARGO1 are not argued to be truly optimal. There is still much room for improvements (in model dynamics, in the forcing, in error statistics, etc) compared with the present estimation system. Hence it may be possible to further reduce $J_{o}$ without over fitting small-scale noise, at any depth, for $\mathrm{T}$ or $\mathrm{S}$. This is most certainly possible for $\mathrm{T}$ near the surface in summer, where $J_{o}$ is larger for ARGO1 than for the climatology (Fig. 4), suggesting that improved forcing and mixed layer parameterization (e.g. Large et al., 1994) are necessary. It is less so for S, which presumably reflects a smaller seasonal influence of surface forcing for $\mathrm{S}$ than for T. Noteworthy, $J_{o}$ does not show any clear increasing trend in ARGO1 over the assimilation window, implying that the impact of model error accumulation over one year is relatively small for this metric.

Decreases in $J_{o}$ are related to changes in the large-scale hydrographic structures. We start with a brief illustration of changes between SPIN and ARGO1 (the differences between the climatology and ARGO1 are discussed in section 6). The most obvious change between SPIN and ARGO1 is in the horizontal gradient of T (and S, not shown) associated with the Gulf Stream-North Atlantic Drift current system (Fig. 5). In SPIN the gradient is excessively smooth, there is a lack of cold water near the coast in the Gulf Stream region, and the current is too zonally oriented east of New Foundland. These features are often seen in such spun-up low-resolution model solutions. SPIN is thus too warm inshore of the correct Gulf Stream position, and too cold offshore (Fig. 1). Upon moving from SPIN to ARGO1, 
the position and sharpness of the horizontal gradients are corrected (Fig. 5) to reduce these misfits to Argo profiles (Fig. 1). Other changes (Fig. 5) that permit to reduce the large-scale misfits to Argo profiles (Fig. 1) include: a) a northward displacement of the 8 to 20 degree isotherms in eastern basins; b) a southeastward displacement of isotherms over the subpolar gyre, where SPIN was too warm; c) a convergence of isotherms to sharpen the Iceland-Scotland and Azores fronts. Section 4 and 5 show that these corrections to the hydrography improve the realism of the circulation.

\section{Estimated horizontal circulation}

The surface geostrophic circulation of ARGO1 is evaluated based on two mean dynamic topography estimates: the one of Rio et al. (2005) (hereafter RSHL05) that uses altimetric (CLS01 average over 1993-1999) and gravimetric (EIGEN-GRACE03S geoid model) satellite measurements alone, and the one of Maximenko and Niiler (2005) (hereafter MN05) that also uses surface drifters. These two estimates are independent of ARGO1, but they are not fully independent of each other because they both use similar sets of altimeter data and a GRACE geoid. Differences between RSHL05 and MN05 provide lower-bound error estimates, which do not account for errors that RSHL05 and MN05 have in common (e.g. some errors inherited from the geoid estimate). In the region where Argo profiles are assimilated, the ARGO1 dynamic topography is significantly more consistent with the independent estimates than is the SPIN dynamic topography (Table 1). Hence, we conclude that assimilating Argo profiles has improved the model dynamic topography. This is especially true for the dynamic topography gradients across the Gulf Stream and between the subtropical and subpolar gyre (Table 2), which are important to basin-scale volume transports. RSHL05 and MN05 are more consistent with each other than with ARGO1 (Tables 1 and 2); Argo and satellite-based mean dynamic topography estimates provide complementary information.

The 2002 average of the decade-long GCM estimate of Stammer et al. (2004) and Köhl et al. (2003) (hereafter SIO02) is taken as a reference to put ARGO1 in perspective. SIO02 and ARGO1 employ the same GCM (MITgcm), estimation method (adjoint), and spatial resolution (one degree), but the experiment duration is longer in Stammer et al. (2004) who estimate forcing corrections. Both Argo profiles and satellite-based dynamic topography (Topex/Poseidon data minus EGM96 geoid) have been assimilated into SIO02, 
and this estimate is therefore not independent of ARGO1, RSHL05 or MN05. SIO02 is significantly more consistent with RSHL05 and MN05 than is ARGO1 in the Gulf Stream region (Table 1, sub-region A), but the opposite is true outside this region (Table 1 , subregion $\mathrm{B}$ ). Provided with this perspective, we conclude that the dynamic topography of ARGO1 (where only hydrography is assimilated) is acceptably consistent with RSHL05 and MN05.

Given that the upper-ocean thermal wind shear is the part of the flow that is most directly constrained by Argo, it follows that velocities at $610 \mathrm{~m}$ in ARGO1 (Fig. 6, right) are in good agreement with independent float drift maps (e.g. Lavender et al., 2000, their Fig. 2a). Both the float drifts and ARGO1 show: a) a meandering of the Gulf Stream-North Atlantic Drift between 40 and $50^{\circ} \mathrm{N}$, between 30 and $40^{\circ} \mathrm{W}$; b) velocities exceeding 5 $\mathrm{cm} \mathrm{s}^{-1}$ along most of the Greenland and Canada coasts, but not over the rest of the subpolar gyre; c) cyclonic recirculations in the Iceland basin (about $32^{\circ} \mathrm{W} 54^{\circ} \mathrm{N}$ ) and in the Labrador basin; d) southward flow from the Labrador current through the Flemish Pass at $47^{\circ} \mathrm{W}$. In general, and especially for each of the previous examples, the $610 \mathrm{~m}$ velocities of ARGO1 (Fig. 6, right) are much more realistic than those of SPIN (Fig. 7, right). In SPIN, the Gulf Stream is too weak, does not separate properly from the coast, and then flows eastward from Newfoundland (Fig. 7). These are well-known deficiencies of low-resolution z-coordinate model prognostic runs, which ARGO1 does not show due to the assimilation of Argo profiles. The assimilation of Argo profiles has improved the subsurface velocity fields. The currents remain generally too wide in ARGO1 though, presumably because of the lack of resolution and the large model viscosity. ARGO1 also lacks the closed recirculation in the Irminger basin found by Lavender et al. (2000).

Horizontal volume transports are improved by the assimilation too. The Gulf Stream transport at $50^{\circ} \mathrm{W}$, computed between 0 and $1000 \mathrm{~m}$, increases from $28 \mathrm{~Sv}$ in SPIN to $43 \mathrm{~Sv}$ in ARGO1 $\left(1 \mathrm{~Sv}=10^{6} \mathrm{~m}^{3} \mathrm{~s}^{-1}\right)$, and thus becomes more consistent with the value of $55 \mathrm{~Sv}$ proposed by Schmitz and McCartney (1993) for water warmer than $7^{\circ} \mathrm{C}$. The subpolar gyre volume transport, integrated from top to bottom, increases from $26 \mathrm{~Sv}$ in SPIN to 30-36 Sv in ARGO1 (30 Sv in the eastern basins, and $36 \mathrm{~Sv}$ in the Labrador sea), which is more consistent with measured ADCP transports in the Labrador Sea (Pickart et al., 2002, $44 \mathrm{~Sv}$ ) and eddy-resolving models (see Treguier et al., 2005, $43 \mathrm{~Sv}$ ). We note that this increase in the subpolar gyre barotropic transport, upon moving from SPIN to ARGO1, is associated with an increase in the density of the water-column within the gyre 
(not shown).

The analysis presented in this section has shown that the horizontal circulation in ARGO1 is fairly realistic, and this is due to the Argo profiles constraint. The Gulf Stream-North Atlantic current system provides a clear example: Argo profiles constrain both the position and the sharpness of the horizontal gradient of $\mathrm{T}$ (Fig. 5), resulting in realistic current path and velocity amplitude (Fig. 6). Over one year, model error does not prevent the successful inversion of a realistic horizontal circulation from real Argo profiles.

\section{Deep flow, overturning and heat transport}

Deep velocities are key contributors to both meridional volume transports and heat transports. Upon moving from SPIN to ARGO1, the deep western boundary current (DWBC) is intensified both in the subtropical and subpolar regions (Fig. 8), making velocities at $3000 \mathrm{~m}$ more consistent with southward spreading rates inferred from tracer distributions or float drifts that are in the range of $1-2 \mathrm{~cm} \mathrm{~s}^{-1}$ (Bower and Hunt, 2000a). The flow through the Charlie-Gibbs fracture zone is realistically westward in ARGO1, whereas it is eastward in SPIN (Fig. 8). ARGO1, unlike SPIN, shows a counterpart to the DWBC in the eastern basin, on the eastern flank of the Mid Atlantic Ridge, as suggested by the inverse model of Paillet et al. (1998) at $1750 \mathrm{~m}$. We thus find that deep velocities are improved by applying the hydrographic observation constraints.

Deep velocity modifications, upon moving from SPIN to ARGO1, are small compared with surface velocity modifications. For a flow that is mostly geostrophic and hydrostatic, this reflects the fact that modifications in water column density and modifications in dynamic topography balance each other to first order. At $3000 \mathrm{~m}$ for example, the standard deviation of the annual mean pressure modification (from SPIN to ARGO1) corresponds to only $1.3 \mathrm{~cm}$, whereas the value for the dynamic topography is $8.2 \mathrm{~cm}$. Therefore the conclusion that deep velocities are improved due to the hydrography constraints can be regarded as a refinement of the previous conclusion for the dynamic topography: the GCM dynamics also handle reasonably well the relatively small imbalance between changes in the water column density and changes in the dynamic topography.

The intensification of the DWBC (Fig. 8) translates, as expected, to an increase and a 
deepening of the southward branch of the main North Atlantic overturning cell and an associated increase in high-latitude deep downwelling (Fig. 9). In the North Atlantic, zcoordinate models generally show spurious mixing in the overflow regions between Greenland and Scotland. This overflow model error propagates southward and eventually results in a too shallow and weak mid-latitude DWBC (and overturning cell), and an underestimated meridional heat transport (see e.g. Willebrand et al., 2001). As expected, SPIN shows these classical deficiencies of z-coordinate model prognostic solutions - ARGO1 does not, even though GCM dynamics have not been improved upon moving from SPIN to ARGO1 (only the initial conditions are modified). This improvement is possible because the large-scale impact of overflow model error is associated with an e-folding time-scale in the 5-10 years range (see Gerdes and Koberle, 1995, and Döscher et al., 1994); over one year, GCM estimates are not expected to be very sensitive to overflow model error. Overflow model error is not reduced per se, but its integrated effect is simply reset via initial condition corrections and limited by the one-year integration time. In this context, the Argo profile constraints on vertical volume transports (see Forget et al., 2007) can be efficient also when using real observations. Similarly, the deep flow tends to upwell as it arrives to the equator in ARGO1 (Fig. 9, middle), as suggested by the inverse model solution of Lux et al. (2001), but not in SPIN (Fig. 9, top).

The advective meridional heat flux ( $\Theta$; appendix: Eq. 4) is also strongly modified upon moving from SPIN to ARGO1 (Fig. 10, left) as a result of the joint modifications of temperature fields (Fig. 5) and velocity fields (Figs. 6, 7 and 8). A classical decomposition of $\Theta$ into overturning component $\left(\Theta_{o v}\right.$; appendix: Eq. 5) and gyre component $\left(\Theta_{g y}\right.$; appendix: Eq. 6) shows that the intensification in $\Theta$ primarily reflects the overturning cell intensification (Fig. 10, right). The modification of the gyre component only dominates the modification of $\Theta$ in the subpolar gyre (Fig. 10, right). In ARGO1, $\Theta$ reaches 1.2 PW between $15^{\circ} \mathrm{N}$ and $30^{\circ} \mathrm{N}$, and is in good agreement with the box model inversion of Ganachaud and Wunsch (2003) between $4^{\circ} \mathrm{S}$ and $47^{\circ} \mathrm{N}$. By contrast, at $24^{\circ} \mathrm{N}$ and $47^{\circ} \mathrm{N}, \Theta$ in SPIN is smaller than the Ganachaud and Wunsch (2003) heat transport estimates by about two of the Ganachaud and Wunsch (2003) error bar estimates. We conclude that assimilation of real hydrographic observations significantly improves the model advective heat flux for the assimilation window length of one year.

Meridional transports are quite different in ARGO1 and SIO02 despite a similar model configuration: SIO02 presents a weaker DWBC at $3000 \mathrm{~m}$ (Fig. 8), a weaker overturning 
rate (Fig. 9) and a weaker meridional heat transport (Fig. 10, left). SIO02 is closer to SPIN than to ARGO1 in that respect, despite observational constraints that include Argo profiles and a climatology. This is consistent with the above discussion of the time-scale associated with overflow model error propagation; GCM estimates are expected to be more sensitive to overflow model error over a decade (e.g. Stammer et al., 2004, and Köhl et al., 2003) than over one year (ARGO1). Furthermore, the subpolar gyre volume transport is also significantly smaller in SIO02 (21-19 Sv) than in ARGO1 (30-36 Sv, see above), and the experiments of Gerdes and Koberle (1995) suggest that overflow model error can cause this reduction. However, the set-up of the two estimation systems leading to SIO02 and ARGO1 differ by more than just the experiment duration, and thus a specific investigation would be required to confirm this interpretation of the differences. The choice of observational constraints, the error asumptions, the uneven availability of data during the nineties, and the choice of adjustable variables could also explain part of the differences between the two 2002-2003 estimates.

To determine the impact of the deep climatological observation constraints, a sensitivity experiment is presented (ARGO0) in which no climatological observation constraint is applied below $2000 \mathrm{~m}$. The main difference between ARGO1 and ARGO0 is that the midlatitude overturning cell is excessively intensified upon moving from SPIN to ARGO0 (Fig. 11). This implies that the meridional heat flux is $0.1 \mathrm{PW}$ larger in ARGO0 than in ARGO1 at mid-latitudes (not shown). The deep hydrography constraint is useful to prevent such artifacts. Despite this difference, Fig. 11 shows that the Argo constraint is responsible for the bulk of the circulation modifications upon moving from SPIN to ARGO1.

Upon moving from SPIN to ARGO1, modifications in initial conditions imply modifications in air-sea heat fluxes through the relaxation terms, but this is not the reason for the modification in $\Theta$. Indeed, using ARGO1 initial conditions and the exact forcing of SPIN, the model solution (ARGO1test) for $\Theta$ is very similar to ARGO1 (Fig. 10 left). If long-term trends in $\mathrm{T}$ were strongly constrained, one would expect the air-sea heat flux to be a more active control of $\Theta$. Over one year, however, the diagnostic of $\Theta$ from subsurface observations can be thought of, simply, as a joint estimation of $\mathrm{v}$ and of $\mathrm{T}$ (also see Forget et al., 2007). 


\section{$6 \quad$ Hydrography in 2002-2003}

In the previous sections, ARGO1 was evaluated using long-term averaged, independent, estimates of the circulation. However, the Argo project objective is to improve our knowledge of the modern ocean state and its low-frequency evolution, upon long-term averaged estimates. Therefore, we now compare ARGO1 and the climatology (Reynaud et al., 1998) to two independent hydrographic sections, and show that ARGO1 better represents contemporary large-scale structures than does the climatology. The two sections, hereafter referred to as GAUSS and OVIDE, were produced respectively by the R/V Gauss between May 22nd and June 9th 2002, and by the R/V Thalassa between June 18th and July 1st 2002. Their positions are indicated in Fig. 5.

In the interior region constrained with Argo profiles, ARGO1 is indeed closer to the GAUSS and OVIDE sections than is the climatology, with the exception of $\mathrm{T}$ near the surface (Table 3). Conclusions are consistent with those for the misfits to the assimilated Argo observations (Fig. 4, section 3), but here independent information is used (the type of instrument and the observed locations differ from the assimilated data set). The GAUSS and OVIDE sections also permit evaluation of ARGO1 close to the coasts where no Argo profiles were assimilated. In these regions, ARGO1 is clearly less consistent with the contemporary ocean than is the climatology. Similar to the findings of Forget et al. (2007), the propagation of Argo constraints into coastal areas is not very efficient for the one-year duration. An inspection of the observed sections and their counterparts in ARGO1 and in the climatology, e.g. for S (Figs. 12 and 13), enables us to discuss the hydrographic structures at stake. Sections of T (not shown) would lead to similar conclusions.

A maximum in $\mathrm{S}$ is observed between 41 and $47^{\circ} \mathrm{W}$ down to $1000 \mathrm{~m}$ (Fig. 12, top) just east of where the GAUSS section crosses the Gulf Stream (Fig. 5B). The depth and width of this feature are more consistent in ARGO1 (Fig. 12, middle) than in the climatology (Fig. 12, bottom). East of this region is a minimum in S, i.e. a dome in isohalines, present at about $33^{\circ} \mathrm{W}$ in both the observed section and in ARGO1, but absent in the climatology (Fig. 12). This dipole pattern corresponds to the meandering of the Gulf Stream across the GAUSS section, which is more pronounced in 2002 than in the climatology (Fig. 14). To the northeast of the domain, the North Atlantic Drift is observed crossing the OVIDE section at $23^{\circ} \mathrm{W}$ (Fig. 13, top). This front appears as a smooth transition in the climatology (bottom), whereas it is consistently sharper and in the correct location in ARGO1 
(middle). The same is true for the horizontal gradient of $\mathrm{S}$ observed at $18^{\circ} \mathrm{W}$ between 800 and $1500 \mathrm{~m}$, which signifies the northwestward limit of the Mediterranean Water plume (Fig. 13). Salinities lower than 34.9 are observed at depth along both the GAUSS and OVIDE sections (Figs. 12 and 13, top), and, above $2000 \mathrm{~m}$, they are correctly reproduced by ARGO1 (middle); they are absent from the climatology sections (bottom) where the deep Labrador Sea Water is slightly saltier and warmer (Table 4). Both horizontal gradients and water mass properties interpolated from Argo, through the GCM dynamics, are more consistent with the ocean in June 2002 than are those of the climatology.

There are some significant discrepancies between ARGO1 and the independent synoptic observations though. First, the observed eddy signals, e.g. Gulf stream eddies (Fig. 12, top) or meddies (Fig. 13, top; in the Mediterranean water plume), cannot be resolved in ARGO1 (middle panels). Second, ARGO1 and the climatology have similar inconsistencies with the independent sections below $2000 \mathrm{~m}$ (Figs. 12 and 13). These inconsistencies are expected, however, because ARGO1 is a fit to the climatology at these depths. Third, the climatology is more consistent with the independent sections than is ARGO1 in some shallow areas, e.g. close to the US (Fig. 12) and Greenland coasts (Fig. 13), where ARGO1 is not directly constrained with observations. Out of these three issues, deep discrepancies are perhaps to be regarded as the most problematic, because deep ocean observations remain very rare.

To further assess the adequacy of the Argo sampling and the model skill as an interpolation tool, a sensitivity experiment is carried out, in which the Argo observations are replaced by their climatological counterparts. The model solution after assimilation (REYN1) is now consistent with the path of the North Atlantic drift (Fig. 14) and the deep Labrador Sea Water properties (Table 4) of the climatology, rather than with ARGO1. Thus, combining GCM dynamics and Argo profiles permits one to distinguish contrasting large-scale oceanic states, within the range of observed oceanic variability. This behavior of the estimation system confirms that the details of the ARGO1 hydrography discussed above, which differ from the climatology, are not an artifact of the sampling characteristics or of model error, but a reflection of the state of the ocean.

As noted previously for the circulation, there are large differences between SIO02 and ARGO1 for the hydrography. For example, the path of the North Atlantic Drift (Fig. 14) and the properties of the deep Labrador Sea Water (Table 4) in SIO02 are out of the 
range set by ARGO1 and the climatology.

\section{$7 \quad$ Summary and discussion}

GCM-based least-squares state estimation has been applied to a set of Argo profiles over the period spring 2002 to spring 2003. The resulting GCM solution not only shows a good agreement with long-term averaged estimates of the hydrography and of the circulation, but also reproduces specifics of the contemporary hydrographic structures beyond the skill of a long-term mean observed climatology. The consistency of the estimates shows that currently available GCMs have useful skills as interpolation-inversion tools when real Argo observations are assimilated over one year. The comparison with previous experiments suggests that the length of the assimilation window is a key parameter: its limitation to one year helps prevent contamination of estimates by the accumulation of model error.

As an inversion tool, the GCM permits one to infer a consistent one-year mean dynamic topography from real Argo profiles, with no ad hoc assumption about a level of no motion. This tool could thus provide an objective way to reduce errors in geoid measurements (e.g. see Jayne, 2006) thanks to Argo. No velocity or sea surface height observational constraints are applied: these results rely only on the skill of the GCM-inversion tool and on the observational constraint of the thermal wind shear. Similarly, the assimilation of real Argo profiles is beneficial to the subsurface velocity fields, and to basin-scale transports. In particular, the deepening and intensification of the North Atlantic overturning cell, and the intensification of the meridional heat flux, are regarded as improvements due to the assimilation. The skill of the GCM-inversion tool is thus found encouraging when using real Argo observations over one year.

Regarding the hydrography, independent (i.e. not assimilated) quasi-synoptic transects have been used to show rigorously that GCM-Argo estimates can better reflect the contemporary position of $\mathrm{T}$ and $\mathrm{S}$ gradients and the contemporary water mass properties than can a long-term mean observed climatology. Relative to the present GCM-Argo estimate, it is believed that there is still large room for improvement - improvements in the estimation system (using a more sophisticated model set-up, adding observational constraints, refining assumptions about errors, etc) that would lead to improvements in the estimates. State of the art GCM estimation efforts to synthesize all available observations 
are expected to be able to make the most of sets of Argo profiles.

It should be emphasized that the conclusions drawn for the hydrography are one step beyond the conclusions drawn for the circulation. Indeed, the improvements in the model circulation due to the assimilation are only discussed relative to the first guess, prognostic, model solution. Even though idealized experiments predict that anomalies in overturning and meridional heat flux can be consistently estimated from sets of Argo profiles, the lack of independent information for such quantities for the real ocean is a major problem. Efforts like the RAPID array or the OVIDE repeated hydrographic transects are therefore regarded as crucial to further test the skill of GCM-Argo estimates (or of GCMobservations estimates more generally). In particular, it remains unclear whether a deep observation strategy analogous to Argo is necessary to diagnose the real ocean circulation variability, and this question demands further investigation. Float observations suggest that the upper ocean hydrography state can control the deep circulation variability in the Gulf Stream region (e.g. see Bower and Hunt, 2000b). Here and in Forget et al. (2007), upper ocean Argo profiles are found to provide efficient constraints on the deep circulation, but this yet has to be confirmed or otherwise for the variability of the real ocean circulation.

Finally, differences with previous GCM estimates have been pointed out. When using a one-degree resolution configuration of a z-coordinate GCM, applying hydrographic observational constraints tends to increase deep flows in one-year assimilation experiments (here for the North Atlantic Ocean, and Ferron and Marotzke, 2003 for the Indian Ocean), whereas decade-long GCM estimates remain close to prognostic model solutions in that respect (as noted by Köhl et al., 2003). In the North Atlantic, low-resolution GCM estimates are expected to be less sensitive to overflow model error over one year than over a decade, as it takes a few years for the associated basin-scale response to develop (e.g. see Gerdes and Koberle, 1995, and Döscher et al., 1994). On the one hand, using such a GCM, it might thus be beneficial to invert the circulation from Argo year by year. On the other hand, extending the skill of GCMs in time is regarded as a crucial research topic, as GCMbased state estimation can provide unique insights on long-term forcing controls of the variability (Stammer et al., 2004) by resolving interannual variability without temporal discontinuities. 


\section{acknowledgments}

Numerical experiments used the NEC SX-5 of the IDRIS (Orsay, France) (project \#031532). Bruno Ferron and Herlé Mercier are supported by CNRS, Gaël Forget by DGA. Additional support was provided by the Groupe Mission Mercator Coriolis.

The in situ profiles where collected and made freely available by the International Argo Project and the national initiatives that contribute to it (http://www.argo.net). They were obtained from the Coriolis data center. Argo is a pilot programme of the Global Ocean Observing System. The MN05 1992-2002 mean ocean dynamic topography data has been obtained from Nikolai Maximenko (IPRC) and Peter Niiler (SIO). The RSHL05 mean ocean dynamic topography was produced by CLS Space Oceanography Division. The SIO02 state estimates were provided by the ECCO Consortium for Estimating the Circulation and Climate of the Ocean funded by the National Oceanographic Partnership Program (NOPP).

\section{Appendix: equations from the companion paper (Forget et al., 2007)}

The estimation problem consists of a minimization of a cost function $J(x)$ that is written as :

$$
J(x)=J_{b}+J_{o}=\left(x-x_{b}\right)^{T} B^{-1}\left(x-x_{b}\right)+\left(y(x)-y_{o}\right)^{T} R^{-1}\left(y(x)-y_{o}\right)
$$

where $x$ are the model initial conditions of temperature $(\mathrm{T})$ and salinity $(\mathrm{S})$, and $x_{b}$ is the first guess estimate for $x ; y_{o}$ and $y(x)$ are the observations and their model counterparts; $B^{-1}$ and $R^{-1}$ are weighting matrices.

The barotropic streamfunction $(\Psi)$ and overturning streamfunction $(\Phi)$ are defined as

$$
\begin{aligned}
& \Psi\left(i_{0}, j_{0}\right)=\sum_{1}^{i_{0}} \sum_{1}^{k_{\max }} v\left(i, j_{0}, k\right) \times a\left(i, j_{0}, k\right) \\
& \Phi\left(j_{0}, k_{0}\right)=\sum_{1}^{i_{\max }} \sum_{1}^{k_{0}} v\left(i, j_{0}, k\right) \times a\left(i, j_{0}, k\right)
\end{aligned}
$$


where $v$ is the meridional velocity, $a$ is the associated model cell surface, and $(i, j, k)$ are grid point indices corresponding to longitude, latitude and depth respectively.

The advective meridional heat transport $\left(\Theta\right.$, Eq. 4), its overturning component $\left(\Theta_{o v}\right.$, Eq. $5)$ and gyre component $\left(\Theta_{g y}\right.$, Eq. 6) are defined as

$$
\begin{aligned}
\Theta\left(j_{0}\right) & =\rho_{0} C_{p} \sum_{1}^{i_{\max }} \sum_{1}^{k_{\max }} v\left(i, j_{0}, k\right) \times T\left(i, j_{0}, k\right) \times a\left(i, j_{0}, k\right) \\
\Theta_{o v}\left(j_{0}\right) & =\rho_{0} C_{p} \sum_{1}^{i_{\max }} \sum_{1}^{k_{\max }} \bar{v}\left(j_{0}, k\right) \times \bar{T}\left(j_{0}, k\right) \times a\left(i, j_{0}, k\right) \\
\Theta_{g y}\left(j_{0}\right) & =\rho_{0} C_{p} \sum_{1}^{i_{\max }} \sum_{1}^{k_{\max }}\left(v\left(i, j_{0}, k\right)-\bar{v}\left(j_{0}, k\right)\right) \times\left(T\left(i, j_{0}, k\right)-\bar{T}\left(j_{0}, k\right)\right) \times a\left(i, j_{0}, k\right)
\end{aligned}
$$

where the overbar denotes a zonal average, $\rho_{0}$ is $1000 \mathrm{~kg} \mathrm{~m}^{-3}$, and $C_{p}$ is $4000 \mathrm{~m}^{2} \mathrm{~kg} \mathrm{~s}^{-2}$. 


\section{References}

Bower, A., Hunt, H., 2000a. Lagrangian observations of the Deep Western Boundary Current in the North Atlantic Ocean. part 1: large-scale pathways and spreading rates. J. Phys. Oceanogr. 30, 764-783.

Bower, A., Hunt, H., 2000b. Lagrangian observations of the Deep Western Boundary Current in the North Atlantic Ocean. part 2: the Gulf Stream-Deep Western Boundary Current crossover. J. Phys. Oceanogr. 30, 784-804.

Döscher, R., Böning, C., Hermann, P., 1994. Response of circulation and heat transport in the North Atlantic to changes in the thermo-haline forcing in northern latitudes : a model study. J. Phys. Oceanogr. 24, 2306-2320.

Ferron, B., Marotzke, J., 2003. Impact of 4d-variational assimilation of WOCE hydrography on the meridional circulation of the Indian Ocean. Deep-Sea Res. 50, 2005-2021.

Forget, G., 2005. Profils ARGO et assimilation 4DVAR pour le suivi climatique de l'oéan Nord Atlantique. Ph.D. thesis.

Forget, G., Ferron, B., Mercier, H., 2007. Combining ARGO profiles with a general circulation model in the North Atlantic. part I: estimation of hydrographic and circulation anomalies from synthetic profiles, over a year. OcMo submitted.

Forget, G., Wunsch, C., 2006. Estimated global hydrographic variability. JPO in press.

Ganachaud, A., Wunsch, C., 2003. Large-scale ocean heat and freshwater transports during the world ocean circulation experiment. J. Climate 16, 696-705.

Gerdes, R., Koberle, C., 1995. On the influence of DSOW in a numerical model of the North Atlantic general circulation. J. Phys. Oceanogr. 25, 2624-2642.

Jayne, S., 2006. Circulation of the north atlantic ocean from altimetry and the gravity recovery and climate experiment geoid. J. Geophys. Res. 111.

Kalnay, E., Kanamitsu, M., Kistler, R., Collins, W., Deaven, D., Gandin, L., Iredell, M., Saha, S., White, G., Woollen, J., Zhu, Y., Chelliah, M., Ebisuzaki, W., Higgins, W., Janowiak, J., Mo, K., Ropelewski, C., Wang, J., Leetmaa, A., Reynolds, R., Jenne, R., Joseph, D., 1996. The NCEP/NCAR 40-year reanalysis project. Bul. Am. Met. Soc. 77 (3), 437-471.

Köhl, A., Stammer, D., Cornuelle, B., Remy, E., Lu, Y., Heimbach, P., Wunsch, C., 2003. The global WOCE synthesis: 1992-2001. Ecco Report Series 20.

Large, W., McWilliams, J., Doney, S., 1994. Oceanic vertical mixing: a review and a model with a nonlocal boundary layer parameterization. Rev. Geophys. 32, 363-403.

Lavender, K., Davis, R., Owens, B., 2000. Mid-depth recirculation observed in the interior 
Labrador and Irminger seas by direct velocity measurements. Nature 407, 66-69.

Lux, M., Mercier, H., Arhan, M., 2001. Interhemispheric exchanges of mass and heat in the Atlantic Ocean in January-March 1993. Deep-Sea Res. 48, 605-638.

Marshall, J., Adcroft, A., Hill, C., Perelman, L., Heisey, C., 1997. A finite-volume, incompressible Navier-Stokes model for studies of the ocean on parallel computers. J. Geophys. Res. 102.

Maximenko, N., Niiler, P., 2005. Hybrid decade-mean global sea level with mesoscale resolution. Recent Advances in Marine Science and Technology.

Paillet, J., Arhan, M., McCartney, M., 1998. Spreading of Labrador Sea Water in the eastern North Atlantic. J. Geophys. Res. 103, 10223-10239.

Pickart, R., Torres, D., Clarke, R., 2002. Hydrography of the Labrador Sea during active convection. J. Phys. Oceanogr. 32, 428-457.

Reynaud, T., Le Grand, P., Mercier, H., Barnier, B., 1998. A new analysis of hydrographic data in the Atlantic and its application to an inverse modeling study. Intern. WOCE News. 32, 29-31.

Rio, M., Schaeffer, P., Hernandez, F., Lemoine, J., 2005. The estimation of the ocean mean dynamic topography through the combination of altimetric data, in-situ measurements and grace geoid: From global to regional studies. Proceedings of the GOCINA Workshop, Luxembourg.

Schmitz, W., McCartney, M., 1993. On the North Atlantic circulation. Rev. Geophys. 31, 29-49.

Stammer, D., Ueyoshi, K., Köhl, A., Large, W., Josey, S., Wunsch, C., 2004. Estimating air-sea fluxes of heat, freshwater and momentum through global ocean data assimilation. JGR 109.

Stammer, D., Wunsch, C., Giering, R., Eckert, C., Heimbach, P., Marotzke, J., Adrcoft, A., Hill, C., Marshall, J., 2002. Global ocean circulation during 1992-1997, estimated from observations and a general circulation model. J. Geophys. Res. 107.

Treguier, A., Theetten, S., Chassignet, E., Penduff, T., Smith, R., Talley, L., Beismann, J., C., B., 2005. Salinity distribution and circulation of the North Atlantic subpolar gyre in high resolution models. J. Phys. Oceanogr. 35, 757-774.

Willebrand, J., Barnier, B., Böning, C., Dieterich, C., Killworth, P., Le Provost, C., Jia, Y., Molines, J., New, A., 2001. Circulation characteristics in three eddy permitting models of the North Atlantic. Prog. Ocean. 48, 123-161. 


\section{List of captions}

Figure 1 : Time averaged misfit to Argo observations for temperature (hereafter T), at $160 \mathrm{~m}$, per model grid cell. Only grid cells that contain at least one Argo measurement are color-shaded. Left panel: before assimilation (hereafter SPIN); right panel: after assimilation (hereafter ARGO1). Also shown in left panel: grid cells where climatological values are assimilated (cross-hatched area).

Figure 3 : Kinetic energy as a function of time, presented as the volume average of $0.5 \times u^{2}$, in $\mathrm{cm}^{2} \mathrm{~s}^{-2}$, computed from weekly mean model outputs. The first (dashed lines) and last (solid lines) iterations are presented for the two steps of the estimation process (see section 2.4). The assimilation window, which is defined as the period when observation constraints are applied, starts in May 2002 (thick vertical line) and is preceded by a two month buffer period.

Figure 2: Uncertainty associated with observations (solid line) and initial conditions (dashed lines), for $\mathrm{T}$ (left) and salinity (hereafter S, right), as a function of depth. Units: ${ }^{\circ} \mathrm{C}$ for $\mathrm{T}$; practical salinity unit for S. For observations, uncertainties are spatially heterogeneous, but only the root mean squared value at each vertical level is shown. For initial conditions, the two steps are associated with different uncertainties (see section 2.4), and are spatially homogeneous.

Figure 4 : Average normalized distance ( $J_{o}$; appendix: Eq. 1$)$ to Argo observations, as a function of time, for $\mathrm{T}$ (left) and $\mathrm{S}$ (right), for the 0-135 $\mathrm{m}$ depth range (upper) and for the 135-2000 m depth range (lower). $J_{o}$ is computed for SPIN, ARGO1 and the climatology (Reynaud et al., 1998).

Figure 5: Annual mean temperature at $160 \mathrm{~m}$, in SPIN (left) and ARGO1 (right). Also shown: thick solid lines locate the GAUSS transect (From the USA to Great Britain) and the OVIDE transect (From Greenland to Portugal) respectively (Figs. 12 and 13); the thick dashed line locates LSW area at $1500 \mathrm{~m}$ (table 4).

Figure 6 : Annual mean dynamic topography (left, in $\mathrm{m}$ ), and velocity at $610 \mathrm{~m}$ (right, in $\mathrm{m} / \mathrm{s}$ ) in ARGO1. The dynamic topography map (left) also shows the regions considered in Table 1, and the locations used in Table 2 ("o", "+", "x" and square signs). Velocities (right) larger than $5 \mathrm{~cm} \mathrm{~s}^{-1}$ are shown using thicker arrows and a different scale, whereas velocities smaller than $0.5 \mathrm{~cm} \mathrm{~s}^{-1}$ are masked (right).

Figure 7 : Same as Fig. 6 but for SPIN.

Figure 8: Annual mean velocity at $3000 \mathrm{~m}$ in SPIN (top), ARGO1 (center) and SIO02 (bottom; defined in section 4). Velocities smaller than $0.2 \mathrm{~cm} \mathrm{~s}^{-1}$ are masked. 
Figure 9 : Annual mean overturning streamfunction ( $\Phi$; appendix: Eq. 3 ) in SPIN (top), ARGO1 (middle) and SIO02 (bottom). Contour interval: $1 \mathrm{~Sv}=10^{6} \mathrm{~m}^{3} \mathrm{~s}^{-1}$.

Figure 10 : Left: annual mean advective heat flux $(\Theta$; appendix: Eq. 4) in the different model solutions. ARGO1test is defined in section 5. The inverse box model estimate of the meridional heat flux of Ganachaud and Wunsch (2003) is also shown (crosses) along with the associated error bars. Right: differences between ARGO1 and SPIN in $\Theta$, in the overturning component of $\Theta\left(\Theta_{o v}\right.$; appendix: Eq. 5), and in the gyre component of $\Theta\left(\Theta_{g y}\right.$; appendix: Eq. 6).

Figure 11 : Difference in annual mean dynamic topography (upper; contour interval: 0.1m) and overturning streamfunction (lower; contour interval $2 \mathrm{~Sv}$ ), between ARGO1 and SPIN (left), and between ARGO0 and SPIN (right). In ARGO0, no climatological observation constraint is applied below $2000 \mathrm{~m}$.

Figure 12 : Instantaneous values of S along the GAUSS section (located by Fig. 5; presented in section 6) as observed (upper), in ARGO1 (middle), and in the climatology (lower). The climatological section is interpolated in time from seasonal means. Contour interval: 0.1.

Figure 13 : Same as Fig. 12 but for the OVIDE section.

Figure 14: Annual mean T (left) and S (right), at 435 m; in ARGO1 (red), in the climatology (blue, thin line), in REYN1 (blue; defined in section 6), and in SIO02 (grey, dashed line). Contours: $9,10,11$, and $12^{\circ}$ (left); 35.3, 35.4, 35.5, and 35.6 (right); both decrease northward. Also shown: the position of the GAUSS section (yellow). 
Table 1

Standard deviation of the difference between mean dynamic topography estimates (defined in section 4) offshore of the $2000 \mathrm{~m}$ isobath computed for the region bounded by $30^{\circ} \mathrm{N}, 64^{\circ} \mathrm{N}$, $10^{\circ} \mathrm{W}$ and $80^{\circ} \mathrm{W}$. The computation is also carried out separately for two sub-regions (see Fig. 6): sub-region A, which includes the Gulf Stream, is to the west of $45^{\circ} \mathrm{W}$ and to the south of $47^{\circ} \mathrm{N}$; sub-region $\mathrm{B}$ is the rest. Unit: $\mathrm{cm}$.

\begin{tabular}{|l|cccc|}
\hline & ARGO1 & SIO02 & SPIN & RSHL05 \\
\hline \hline MN05 & 9.0 & 7.4 & 12.4 & 3.8 \\
\hline RSHL05 & 7.6 & 6.8 & 11.4 & \\
\hline \hline MN05, sub-region A & 11.0 & 6.9 & 13.7 & 5.1 \\
\hline RSHL05, sub-region A & 8.5 & 5.0 & 12.5 & \\
\hline \hline MN05, sub-region B & 6.5 & 7.4 & 11.3 & 3.4 \\
\hline RSHL05, sub-region B & 5.2 & 7.0 & 10.5 & \\
\hline
\end{tabular}

Table 2

Difference in dynamic topography, between the subtropical maximum and: the subpolar minimum ( $\Delta$ gyre), or $39^{\circ} \mathrm{N}-71^{\circ} \mathrm{W}$ ( $\Delta$ Gulf Stream), or $33^{\circ} \mathrm{N}-15^{\circ} \mathrm{W}$ ( $\Delta$ subtropical). For the subtropical maximum and the subpolar minimum, precise locations are shown on Fig. 6 as circles (for RSHL05), squares (for MN05), " " signs (for ARGO1 and SPIN) and "x" signs (for SIO02). For each of the two other end-points, the exact same location is used for the four estimates and the four signs are overlaid. Unit: $\mathrm{cm}$.

\begin{tabular}{|l|ccccc|}
\hline & ARGO1 & SIO02 & SPIN & RSHL05 & MN05 \\
\hline$\Delta$ gyre & 139 & 145 & 106 & 133 & 137 \\
$\Delta$ Gulf Stream & 85 & 75 & 45 & 72 & 77 \\
$\Delta$ subtropical & 49 & 62 & 48 & 56 & 54 \\
\hline
\end{tabular}


Table 3

Average normalized distance ( $J_{o}$; appendix: Eq. 1) to the independent section observations (GAUSS and OVIDE), computed for ARGO1 and for the climatology. For each section, the observations are split into interior values and coastal values, which are separated by the $2000 \mathrm{~m}$ isobath. The GAUSS and OVIDE observations have not been assimilated.

\begin{tabular}{|l|cccc|}
\hline & ARGO1, T & climatology, T & ARGO1, S & climatology, T \\
\hline \hline GAUSS, interior, 0-135 m & 1.1 & 2.0 & 1.5 & 2.1 \\
\hline GAUSS, interior, 135-2000 m & 2.0 & 3.5 & 1.7 & 3.2 \\
\hline GAUSS, coastal & 3.4 & 0.7 & 2.7 & 0.9 \\
\hline \hline OVIDE, interior, 0-135 m & 2.6 & 1.5 & 1.2 & 1.8 \\
\hline OVIDE, interior, 135-2000 m & 1.8 & 2.6 & 1.7 & 2.3 \\
\hline OVIDE, coastal & 3.5 & 4.9 & 4.9 & 2.8 \\
\hline
\end{tabular}

Table 4

Annual mean T and S at $1500 \mathrm{~m}$, spatially averaged over the LSW area. The LSW area, located on Fig. 5, is defined as the area where $2^{\circ} \mathrm{C}<T<4{ }^{\circ} \mathrm{C}$ and $34.8<S<34.95$ in the annual mean ARGO1 fields. REYN1 is defined in section 6.

\begin{tabular}{|c|cccc|}
\hline & ARGO1 & REYN1 & climatology & SIO02 \\
\hline $\mathrm{T}$ & 3.34 & 3.46 & 3.43 & 3.79 \\
$\mathrm{~S}$ & 34.89 & 34.92 & 34.92 & 34.93 \\
\hline
\end{tabular}


Fig. 1. Time averaged misfit to Argo observations for temperature (hereafter T), at $160 \mathrm{~m}$, per model grid cell. Only grid cells that contain at least one Argo measurement are color-shaded. Left panel: before assimilation (hereafter SPIN); right panel: after assimilation (hereafter ARGO1). Also shown in left panel: grid cells where climatological values are assimilated (cross-hatched area).
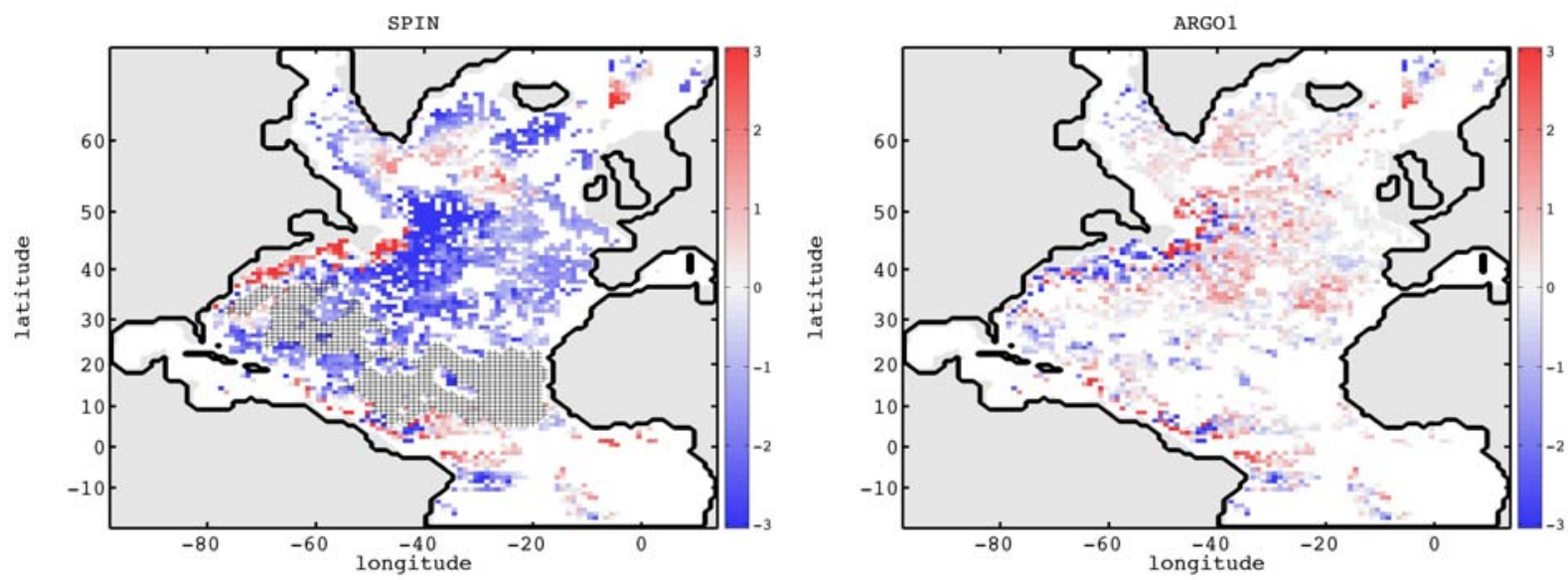

Fig. 2. Uncertainty associated with observations (solid line) and initial conditions (dashed lines), for $\mathrm{T}$ (left) and salinity (hereafter $\mathrm{S}$, right), as a function of depth. Units: ${ }^{\circ} \mathrm{C}$ for $\mathrm{T}$; practical salinity unit for S. For observations, uncertainties are spatially heterogeneous, but only the root mean squared value at each vertical level is shown. For initial conditions, the two steps are associated with different uncertainties (see section 2.4), and are spatially homogeneous.
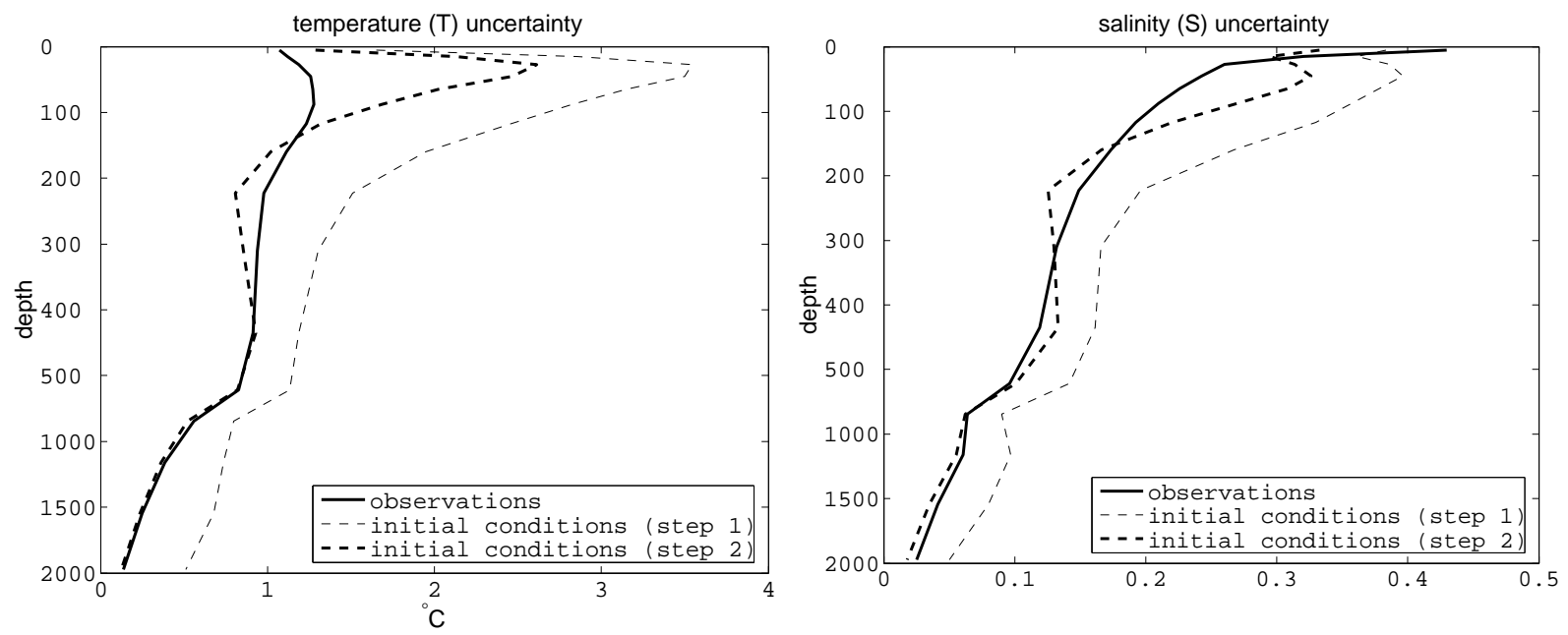
Fig. 3. Kinetic energy as a function of time, presented as the volume average of $0.5 \times u^{2}$, in $\mathrm{cm}^{2} \mathrm{~s}^{-2}$, computed from weekly mean model outputs. The first (dashed lines) and last (solid lines) iterations are presented for the two steps of the estimation process (see section 2.4). The assimilation window, which is defined as the period when observation constraints are applied, starts in May 2002 (thick vertical line) and is preceded by a two month buffer period.

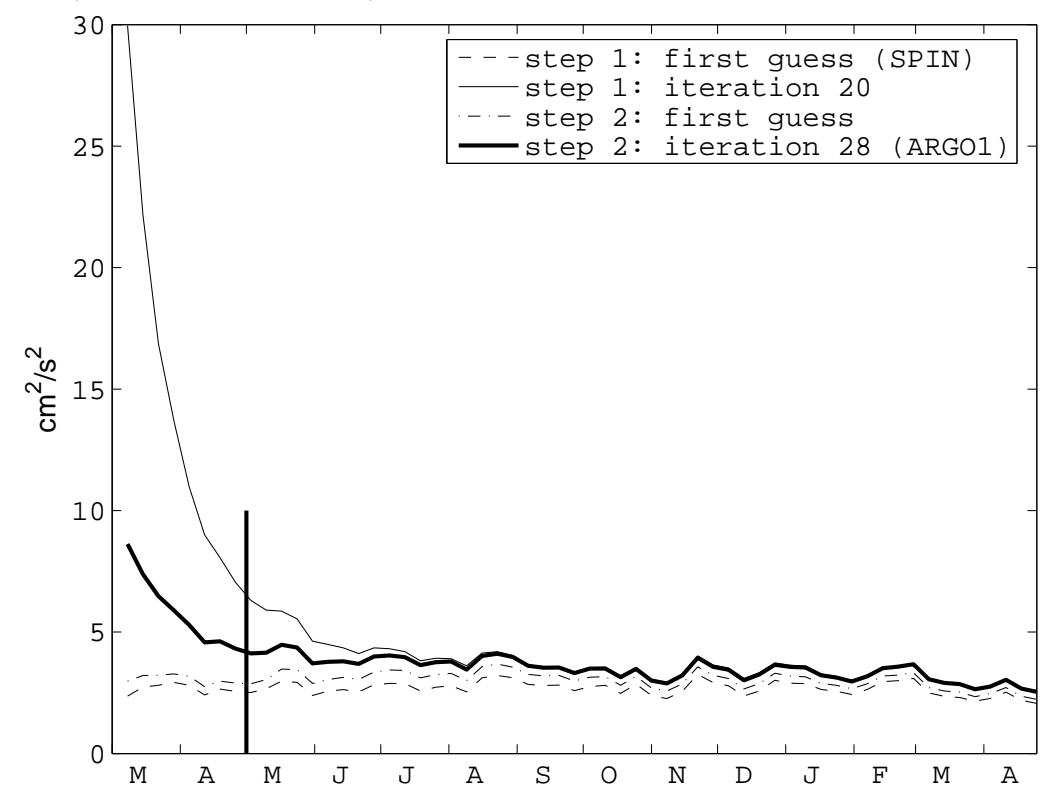


Fig. 4. Average normalized distance ( $J_{o}$; appendix: Eq. 1) to Argo observations, as a function of time, for $\mathrm{T}$ (left) and $\mathrm{S}$ (right), for the 0-135 $\mathrm{m}$ depth range (upper) and for the 135-2000 $\mathrm{m}$ depth range (lower). $J_{o}$ is computed for SPIN, ARGO1 and the climatology (Reynaud et al., 1998).
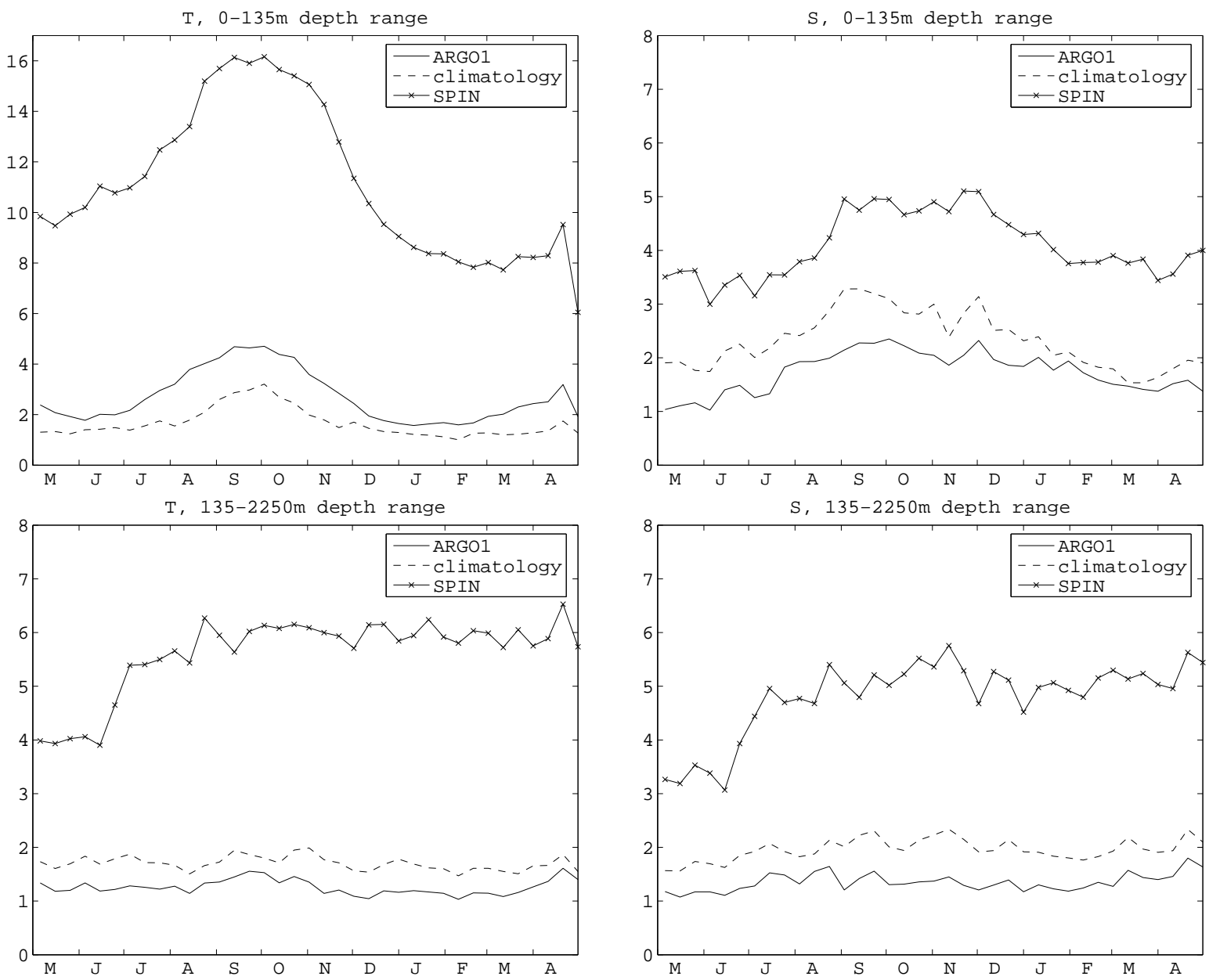
Fig. 5. Annual mean temperature at $160 \mathrm{~m}$, in SPIN (left) and ARGO1 (right). Also shown: thick solid lines locate the GAUSS transect (From the USA to Great Britain) and the OVIDE transect (From Greenland to Portugal) respectively (Figs. 12 and 13); the thick dashed line locates LSW area at $1500 \mathrm{~m}$ (table 4).
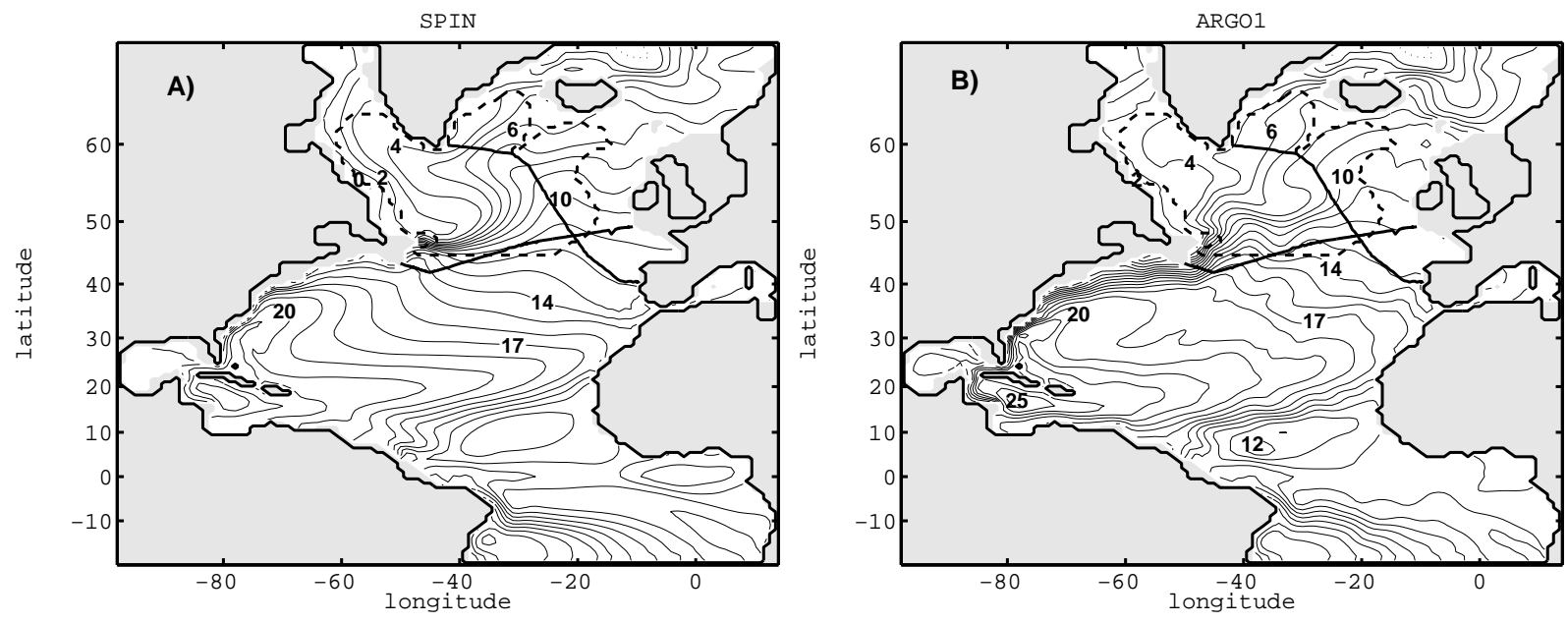

Fig. 6. Annual mean dynamic topography (left, in $\mathrm{m}$ ), and velocity at $610 \mathrm{~m}$ (right, in $\mathrm{m} / \mathrm{s}$ ) in ARGO1. The dynamic topography map (left) also shows the regions considered in Table 1, and the locations used in Table 2 ("o", " +", "x" and square signs). Velocities (right) larger than 5 $\mathrm{cm} \mathrm{s}^{-1}$ are shown using thicker arrows and a different scale, whereas velocities smaller than 0.5 $\mathrm{cm} \mathrm{s}^{-1}$ are masked (right).
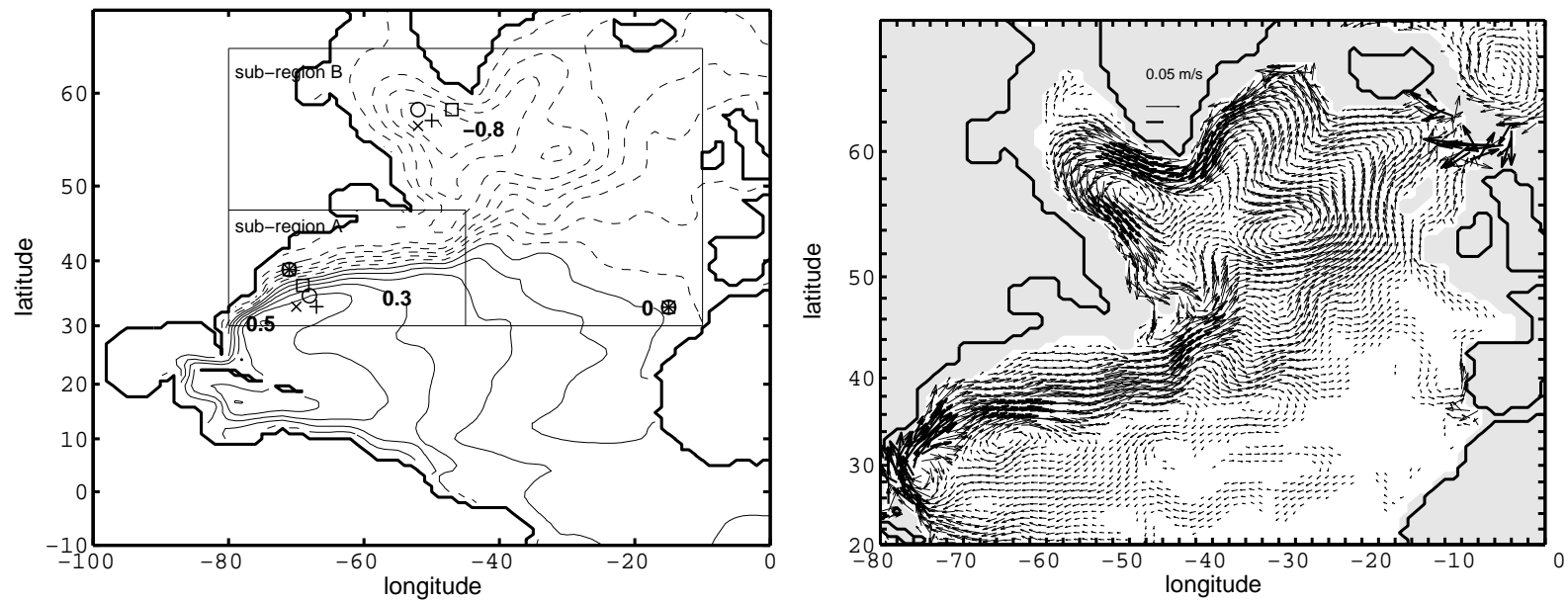
Fig. 7. Same as Fig. 6 but for SPIN.
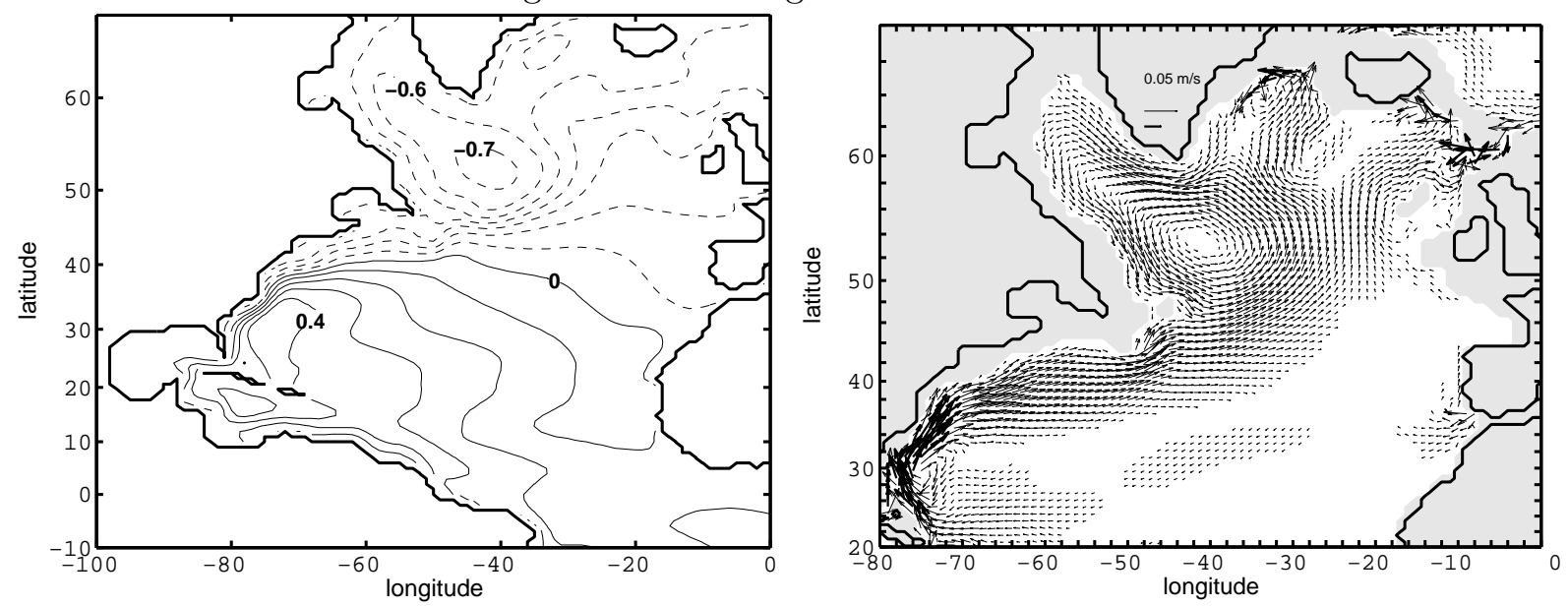
Fig. 8. Annual mean velocity at $3000 \mathrm{~m}$ in SPIN (top), ARGO1 (center) and SIO02 (bottom; defined in section 4). Velocities smaller than $0.2 \mathrm{~cm} \mathrm{~s}^{-1}$ are masked.
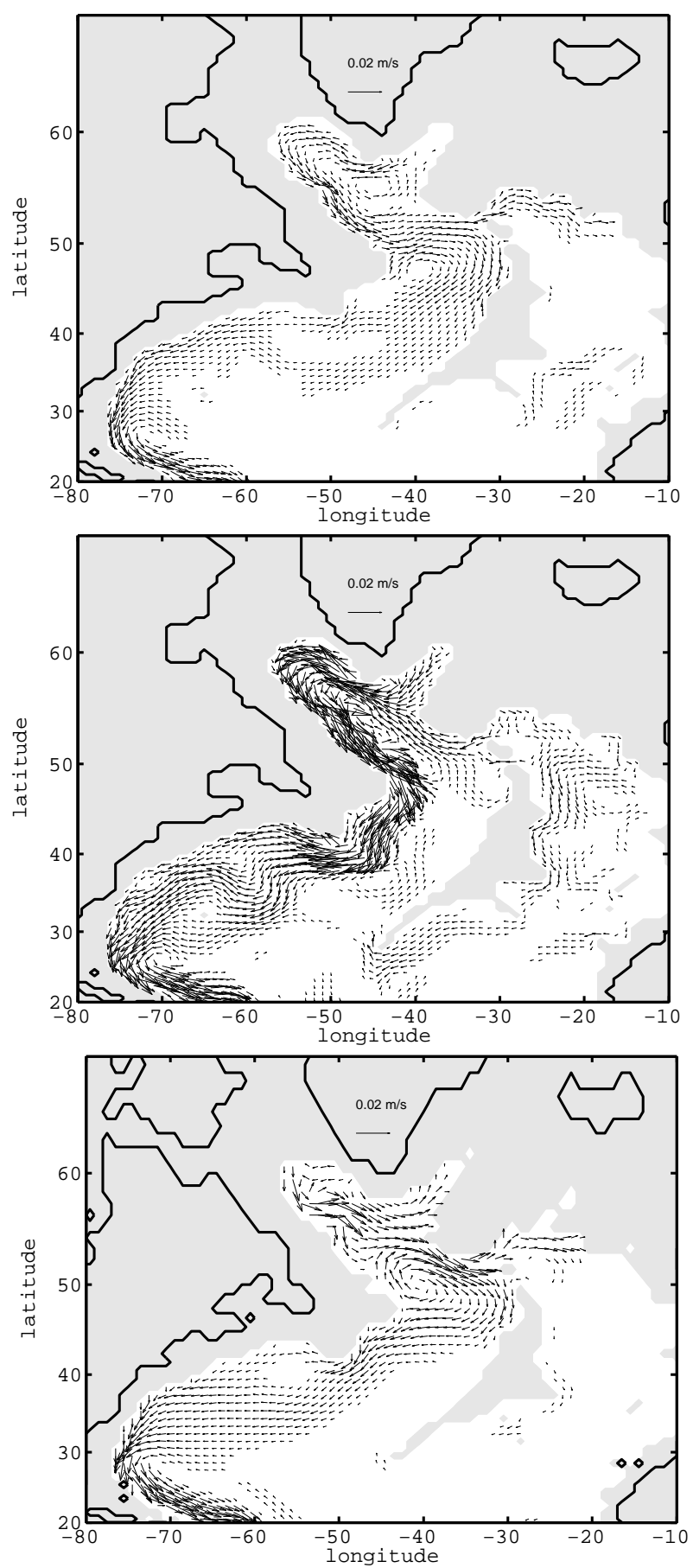
Fig. 9. Annual mean overturning streamfunction ( $\Phi$; appendix: Eq. 3) in SPIN (top), ARGO1 (middle) and SIO02 (bottom). Contour interval: $1 \mathrm{~Sv}=10^{6} \mathrm{~m}^{3} \mathrm{~s}^{-1}$.
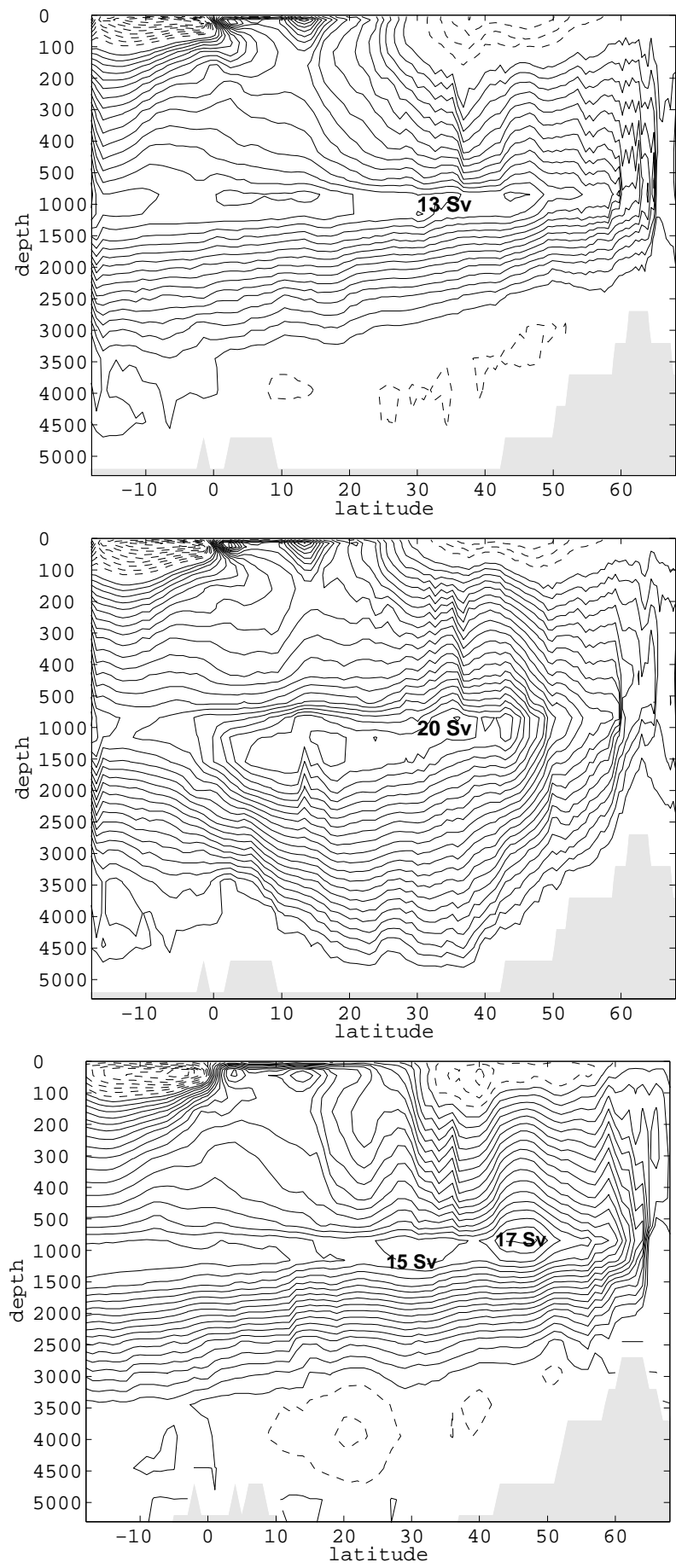
Fig. 10. Left: annual mean advective heat flux $(\Theta$; appendix: Eq. 4) in the different model solutions. ARGO1test is defined in section 5. The inverse box model estimate of the meridional heat flux of Ganachaud and Wunsch (2003) is also shown (crosses) along with the associated error bars. Right: differences between ARGO1 and SPIN in $\Theta$, in the overturning component of $\Theta\left(\Theta_{o v}\right.$; appendix: Eq. 5), and in the gyre component of $\Theta\left(\Theta_{g y}\right.$; appendix: Eq. 6).
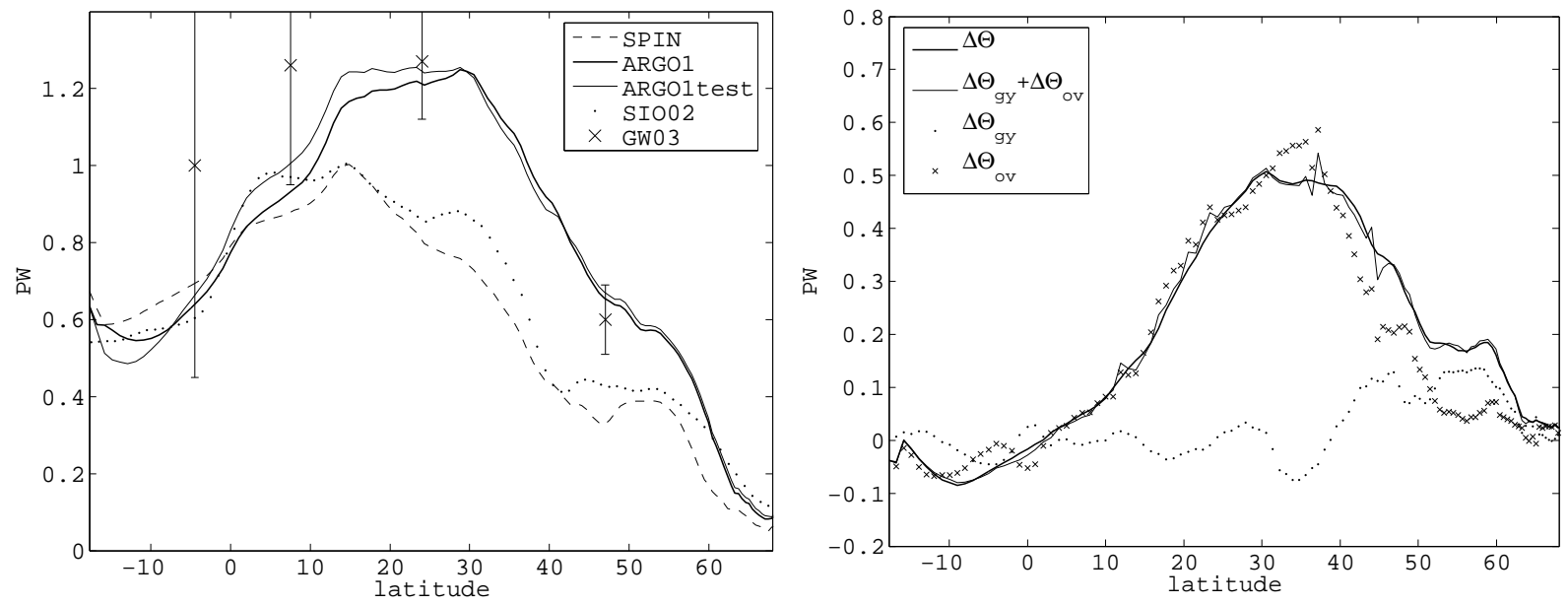
Fig. 11. Difference in annual mean dynamic topography (upper; contour interval: $0.1 \mathrm{~m}$ ) and overturning streamfunction (lower; contour interval $2 \mathrm{~Sv}$ ), between ARGO1 and SPIN (left), and between ARGO0 and SPIN (right). In ARGO0, no climatological observation constraint is applied below $2000 \mathrm{~m}$.
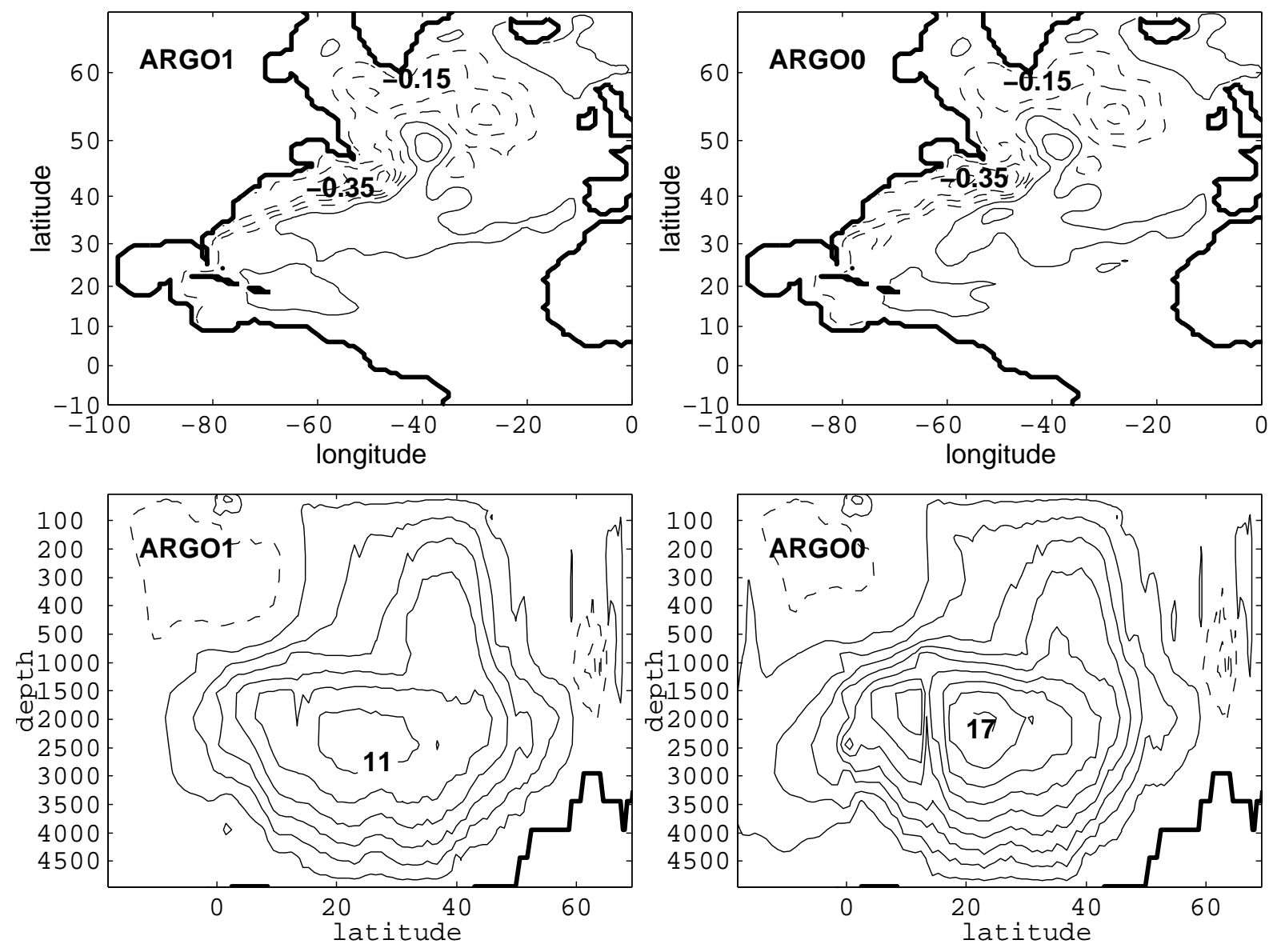
Fig. 12. Instantaneous values of $\mathrm{S}$ along the GAUSS section (located by Fig. 5; presented in section 6) as observed (upper), in ARGO1 (middle), and in the climatology (lower). The climatological section is interpolated in time from seasonal means. Contour interval: 0.1.
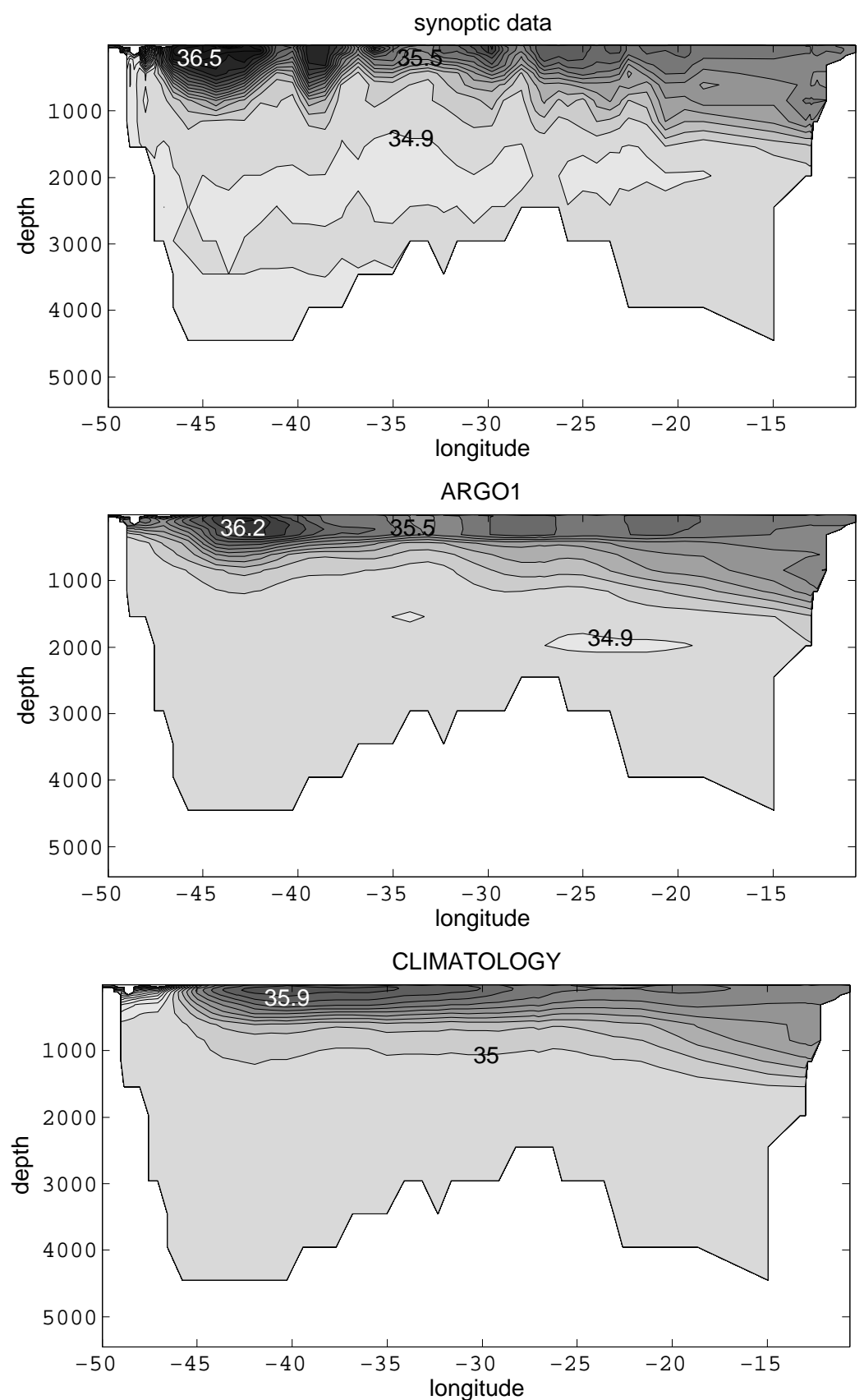
Fig. 13. Same as Fig. 12 but for the OVIDE section.
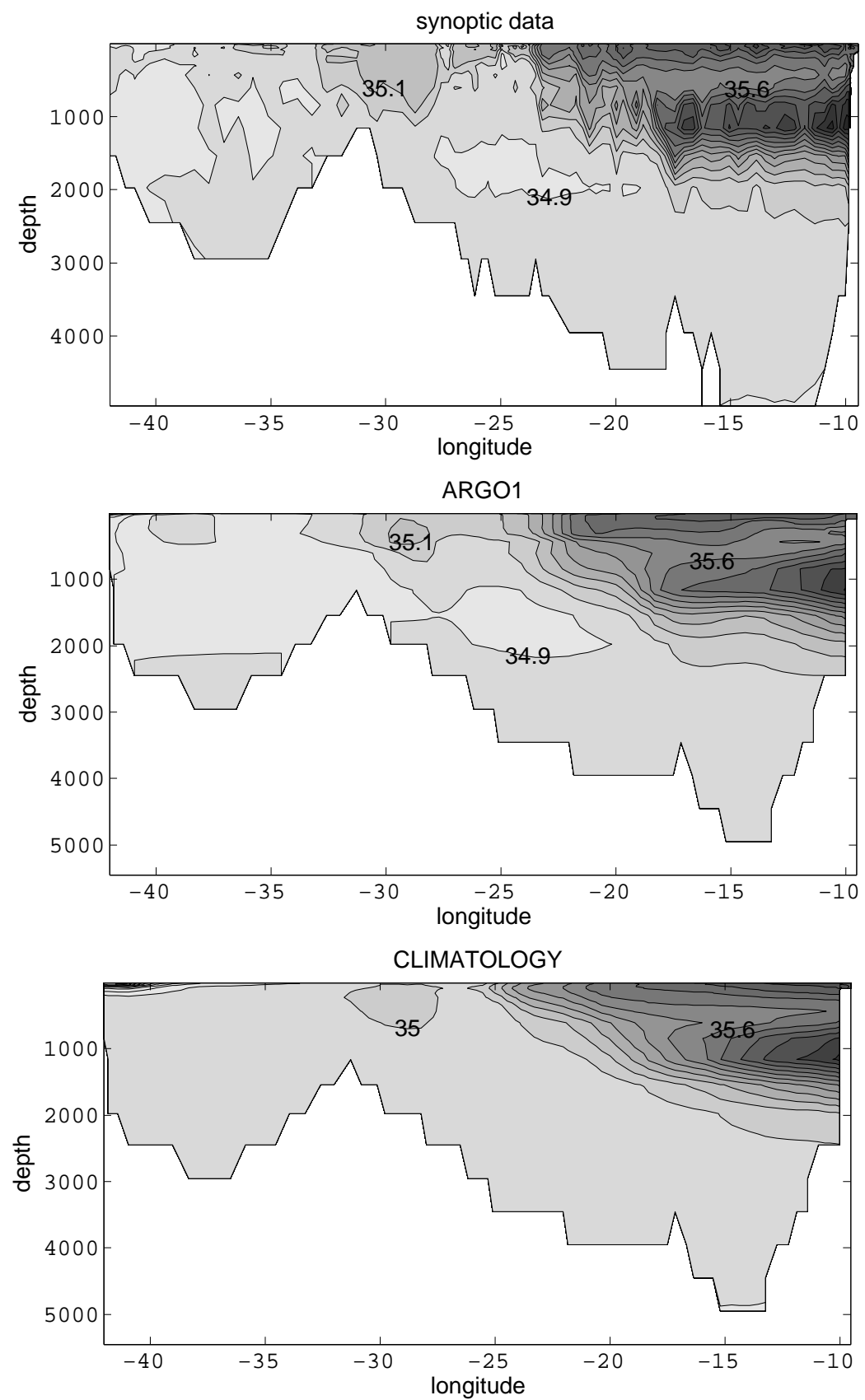
Fig. 14. Annual mean T (left) and S (right), at $435 \mathrm{~m}$; in ARGO1 (red), in the climatology (blue, thin line), in REYN1 (blue; defined in section 6), and in SIO02 (grey, dashed line). Contours: 9, 10, 11, and $12^{\circ}$ (left); 35.3, 35.4, 35.5, and 35.6 (right); both decrease northward. Also shown: the position of the GAUSS section (yellow).
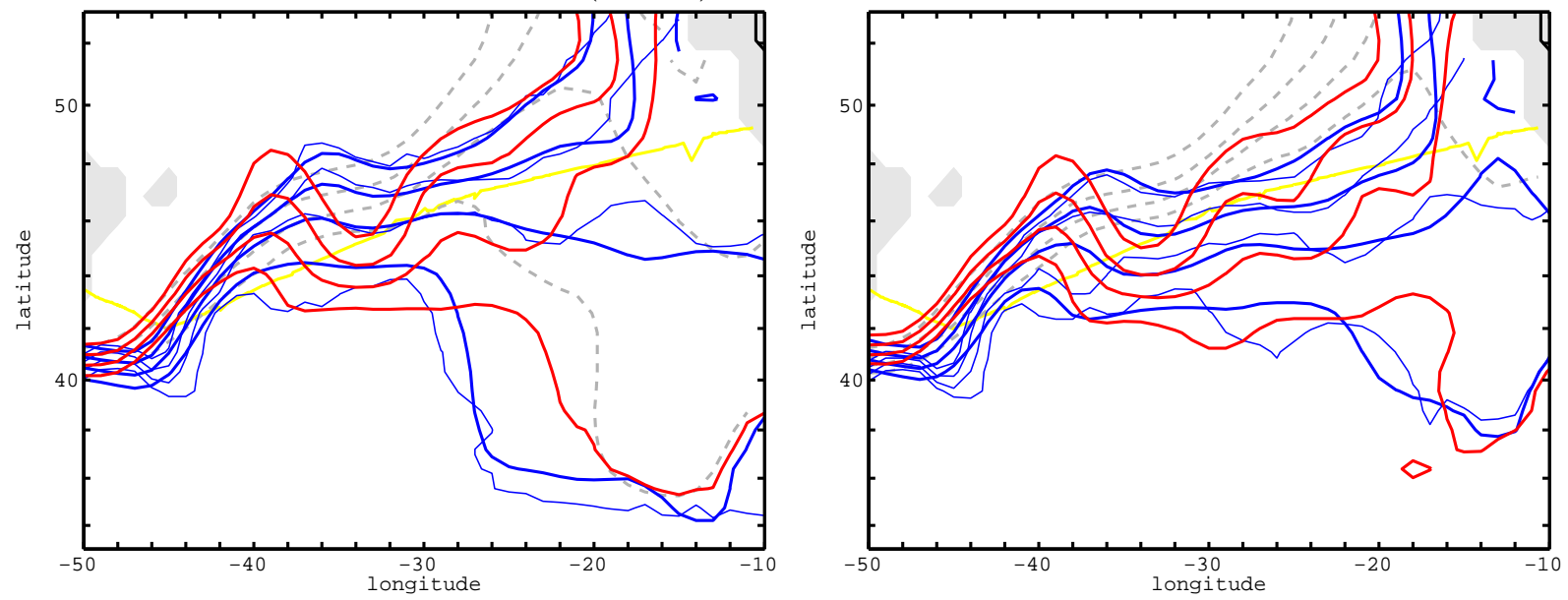